OPEN ACCESS

Edited by:

Deepa S. Subramaniam,

MedStar Georgetown University Hospital, United States

Reviewed by:

K. Shilo,

The Ohio State University, United States

Timothy F. Burns,

University of Pittsburgh Cancer Institute, United States

*Correspondence:

Anna M. Morell

a.mariamorelli@gmail.com

Specialty section:

This article was submitted to

Thoracic Oncology,

a section of the journal

Frontiers in Oncology

Received: 29 March 2018 Accepted: 04 July 2018

Published: 27 July 2018

Citation:

Turkaj A, Morelli AM, Vavalà T and Novello S (2018) Management of Leptomeningeal Metastases in

Non-oncogene Addicted Non-small Cell Lung Cancer. Front. Oncol. 8:278. doi: 10.3389/fonc.2018.00278

\section{Management of Leptomeningeal Metastases in Non-oncogene Addicted Non-small Cell Lung Cancer}

\author{
Ana Turkaj ${ }^{1}$, Anna M. Morelli ${ }^{1 *}$, Tiziana Vavalà ${ }^{2}$ and Silvia Novello ${ }^{1}$ \\ ${ }^{1}$ Department of Oncology, University of Torino, Ospedale San Luigi Gonzaga, Orbassano, Italy, ${ }^{2}$ SC of Oncology, ASL CN1, \\ Ospedale Civile di Saluzzo, Saluzzo, Italy
}

Brain metastases in non-small cell lung cancer (NSCLC) patients are more often detected due to imaging modalities improvements but also emerge because of improved treatments of the primary tumor which lead to a longer survival. In this context, development of leptomeningeal metastases (LM) is a devastating complication and its prognosis remains poor despite advances in systemic and local approaches. Histology characterization of NSCLC and molecular expression influence LM management. For those with "oncogene addiction," new generation epidermal growth factor receptor (EGFR) and anaplastic lymphoma kinase (ALK) tyrosine kinase inhibitors (TKIs) were developed to strongly penetrate the blood-brain barrier (BBB) with the aim to prevent central nervous system cancer dissemination, eventually impacting on LM appearance and its subsequent management. Systemic chemotherapy, often combined with intrathecal chemotherapy (when possible), was one of common indications for lung cancer patients affected by $L M$, without driver mutations and a good performance status but currently, with the advent of innovative systemic approaches treatment solutions in this subgroup of patients are rapidly evolving. Whole brain radiation therapy (WBRT) is the conventional treatment for patients with brain metastases. Furthermore, modern radiation techniques, as stereotactic radiotherapy (SRT), improve outcomes in those cases with a limited number of lesions. However, LM represent a minority of CNS metastases and few literature data are available to drive the radiotherapy approach. Considering all relevant progress made in this setting, after a literature review, the aim of this paper is to discuss about recent developments and therapeutic options in LM management of non-oncogene addicted NSCLC.

Keywords: non-small cell lung cancer (NSCLC), brain metastases, leptomeningeal metastases, chemotherapy, intra-thecal chemotherapy, immunotherapy, radiotherapy

\section{INTRODUCTION}

Non-small cell lung cancer (NSCLC) is characterized by a high incidence of central nervous system (CNS) dissemination, with approximately $40 \%$ of patients developing brain metastases (BM) in the course of their disease $(1,2)$ and leptomeningeal metastases (LM) appearance in a smaller percentage (3-5\%) (3). Particularly, LM incidence among NSCLC patients is 3.8\% more frequent in adenocarcinoma subtype, with about a third of those patients having concomitant BM (4). LM usually manifest as a late complication, which have been reported to emerge as late as up to 112 
months after initial diagnosis (5). LM cases are increasing in incidence as a result of improved survival in subgroups of patients with targetable mutations treated with molecular therapies, but also because of modern neuro-imaging tools, able to clearly identify even small foci of meningeal dissemination (6-8). Median survival of NSCLC patients affected by LM is particularly poor even with signs of improvement, from a historical median survival of 1-3 to 3-11 months with novel therapies and integration of local and systemic treatments (9). Specific treatments of LM depends on histology characterization of NSCLC, molecular expression, time of appearance and patient's performance status. Molecularly targeted therapies and immunotherapy showed antitumor activity for brain metastases although effectiveness in cytologically confirmed and symptomatic LM is still limited or unknown (3). Systemic and intrathecal (IT) chemotherapy with site-specific radiotherapy are usually applied, particularly in non-oncogene addicted NSCLC, while up to one-third of the patients are treated with best supportive care alone. Despite the lack of the standard treatments, active treatments have been associated independently with longer overall survival (OS) (10). Recent advances in the understanding of LM biology in NSCLC patients along with the development of highly active targeted drugs for tumors with specific genetic alterations, helped to redefine the prognosis in this subgroup of patients and the same evolution is largely awaited in those NSCLC patients without oncogene addiction $(5,11-14)$. Based on literature review, this paper aims to discuss about recent developments and therapeutic options of LM in NSCLC patients without driver mutations.

\section{BIOLOGY OF BLOOD BRAIN BARRIER AND DRUG DELIVERY}

The blood-brain barrier (BBB) is constituted by a continuous stratum of endothelial cells connected by tight junctions surrounded by pericytes and perivascular end feet of astrocytes, thus being a highly selective barrier which separates systemic circulation from cerebrospinal fluid (CSF) (15).

BBB maintains CNS homeostasis by enabling the transport of selected substances only, through a combined result of influx and efflux mechanisms. Therapeutic efficacy in this area is determined by whether drug concentrations can be achieved in the CSF and these differ as a result of multiple conditions. The ability of a drug to cross the BBB is substantially improved by particular physic-chemical properties, including low potential for active efflux, few rotatable bonds, small polar surface area, few hydrogen bond donors (9). For instance, anticancer therapeutics (tyrosine kinase inhibitors or chemotherapeutic agents), are substrates of efflux transport proteins, such as Pglycoprotein, which is responsible for the transport of most drugs outside the intracranial region. Most chemotherapy agents have low CSF concentrations, with relevant liquor permeability reported only for temozolomide, methotrexate and topotecan (16-19), however predicted CNS penetration does not necessary correlate with known response rates to chemotherapeutic agents. Moreover, free diffusion of molecules across the $\mathrm{BBB}$ requires both lipophilicity and low molecular weight (less than $0.5 \mathrm{kDa}$ ): chemotherapy drugs are usually larger than $150 \mathrm{kDa}$, hydrophilic and frequently protein-bound molecules, therefore unable to penetrate an intact BBB (2023). In this context, growing scientific evidence highlights that CNS metastases cause BBB interruption; this process, probably due to tumor neo-angiogenesis, lead to generate new vessels lacking of structural and physiological features of normal $\mathrm{BBB}$, thus favoring the passage of drugs into the brain (24, 25). The same hypothesis emerges after whole brain radiation (WBRT) approach, thus providing a biologic rationale for using concomitant or sequential systemic and local treatments in these cases $(26,27)$.

\section{DIAGNOSIS OF LEPTOMENINGEAL METASTASES}

LM involve penetration of inner layers of meninges and subarachnoid space in which CSF circulates. Its diagnosis is specifically based on three different assessments: clinical signs and symptoms, CSF cytological examinations and neuroradiological imaging.

Early clinical presentation can be subtle and may include headaches and back pain, cranial nerve deficits, cauda equine symptoms or signs, visual disturbances, diplopia, hearing loss and neurocognitive syndromes. In later stages, symptoms related to elevated intracranial pressure could occur $(28,29)$. Cytological identification of malignant cells in CSF is the gold standard for diagnosis of LM. The sensitivity of the initial lumbar puncture was reported to be as low as $50 \%$, with a potential increase to $75-85 \%$ with a second CSF analysis (30). A meningeal biopsy is rarely needed to confirm a clinical suspect. A recent study performed by Jiang et al. demonstrated that the use of nextgeneration sequencing (NGS) performed on cerebrospinal fluid circulating tumor cells (CSF-CTC) may be a more sensitive and an effective way to diagnose LM, serving also as a liquid biopsy for gene profiles in NSCLC patients with LM (31). Besides clinical and cytological diagnosis, brain and spine imaging are able to identify involved sites, even in cytology-negative cases (32).

Magnetic resonance imaging (MRI), ideally with a 3 Tesla scanner is the most useful imaging modality for the detection of LM. Both T1 with and without contrast enhancement and high resolution $\mathrm{T} 2$ fluid attenuated inversion recovery sequences postcontrast are important in establishing a radiological diagnosis of LM.

Particularly the disruption of $\mathrm{BBB}$ in presence of CNS metastases is often evidenced by peritumoral edema and accumulation of contrast during the imaging scans and, as more recently observed, penetration of CNS metastases is identified by nuclear medicine tracers, such as 18 -Sodium Fluoride (33).

The EANO-ESMO clinical practice guidelines propose to classify LM by using two major criteria, being "type I" those LM when the diagnosis has been verified citologically or histologically and "type II" in the absence of verification. While on the basis of the neuroimaging findings: linear leptomeningeal disease (type A), nodular leptomeningeal disease (type B), both (type C) or 
neither nor, e.g., no neuroimaging evidence of LM except possibly hydrocephalus (type D) (34).

\section{TREATMENT OPTIONS OF LEPTOMENINGEAL METASTASES}

Treatment of LM is preferentially multidisciplinary and mostly indicated when diagnosis is unequivocal or symptoms are strongly suggestive, in case of negative cytology.

The goals of treatment in patients with LM are to improve or stabilize the neurologic status of the patient, maintain or regain quality of life and optimally to prolong survival together with marginal toxicity. Limited data are available to establish treatment recommendations in the management of LM: no randomized trials proved a survival benefit of a specific treatment modality and, accordingly, the optimal strategy is still poorly defined, particularly in non-oncogene addicted NSCLC. In this last setting of patients, palliative radiotherapy to symptomatic sites of disease, cytotoxic chemotherapies, intrathecal therapy (or a combination of these modalities) are traditionally considered, with the new innovative immunotherapy chance (35-39).

\section{Radiation Therapy}

In the era of improved radiation modalities, local treatment of BM is rapidly improving: a growing amount of data support an integrate use of WBRT or stereotactic radiosurgery (SRS) with systemic treatment in a variety of clinical scenarios, together with alternative radiation approaches, such as intensity modulated radiation therapy (IMRT) or even proton beam therapy, when applicable (40-42).

LM represent a minority of CNS metastases $(11-20 \%)(43,44)$ and less data are available to inform decisions about therapy. RT is mainly administered for symptoms alleviations, CSF flow correction or for debulking to facilitate chemotherapy.

WBRT is typically used in cases of concurrent brain metastases or major meningeal cerebral involvement (45). For BM dose and fractionation scheme is at the discretion of the treating radiation oncologist, though most commonly used dose and fractionation schemes are $20 \mathrm{~Gy}$ in 5 fractions of $4 \mathrm{~Gy}$ (standard schedule in Europe) and $30 \mathrm{~Gy}$ in 10 fractions of $3 \mathrm{~Gy}$ (46). For LM focal radiation therapy is recommended on symptomatic, bulky or obstructive sites and the dose depends on performance status $(20-40 \mathrm{~Gy}$ in 520 fractions), volume to treat and available techniques (47). Different studies reported a survival difference in favor of patients with better performance status after various treatments, including WBRT $(48,49)$. Gani et al. evidenced that WBRT alone in patients with LM from breast and lung cancer is an effective palliative treatment for patients unfit for chemotherapy and poor performance status (49). As tumor dissemination affects the whole CSF compartment, according to some studies, the complete craniospinal axis should be encountered as target volume. Favorable results have been reported in small series. To determine the effects of craniospinal irradiation (CSI) a retrospective study of 16 patients with LM (mostly from breast and lung cancer) was conducted by Hermann et al. In this study, ten patients were additionally treated with intrathecal methotrexate. The authors conclude that craniospinal radiotherapy is feasible and effective for palliative treatment of LM (36).

However, craniospinal irradiation (CSI) is generally not recommended, as it is assumed to cause substantial myelotoxicity. In fact, in his review, Chamberlain stated that "whole neuroaxis radiation of the craniospinal axis is rarely indicated in the treatment of LM in solid tumors" (50).

Conformal radiotherapy may help to limit bone marrow and neurotoxicity making focal radiotherapy better tolerated. Proton therapy is only available in a few centers, but this approach promises further reduction of toxicity and effectiveness from CSI $(51,52)$.

Focal RT administration in fractionated regimens, such as involved-field or stereotactic RT or administered in single fractions (radiosurgery), can be used to treat nodular disease and symptomatic cerebral or spinal sites (34). By contrast, stereotactic radiosurgery (SRS), which is a radiation therapy technique in which multiple focused radiation beams intersect over a target, results in delivery of a highly conformal, high-dose of radiation to the target and minimal radiation to the surrounding normal tissues. In patients with BM a Gamma Knife Radiosurgery (GKRS) is typically used, depending upon the volume and location prescription doses typically range from 15 to $24 \mathrm{~Gy}$ for single fraction session (53). GKRS allow to achieve high rates of local control, and is able to delay the need for WBRT thus avoid potential neurocognitive toxicities, although a phase 2 RTOG study suggested that concomitant administration of memantine together with WBRT may reduce and delay subsequent cognitive consequences (54). Few studies have reported on the role of SRS in the setting of $\operatorname{LM}(55,56)$. In the small and heterogeneous study by Wolf et al. the prescription tumor margin dose was a median of $16 \mathrm{~Gy}$ (11-20 Gy) to the $50-80 \%$ isodose volumes. The authors suggested SRS capable to provide high rates of local control for restricted LM with a median survival of 10 months and with $60 \%$ of the population alive at 6 months. SRS for focal LM is preferable in those patients who are eligible for systemic therapy, including immuno-therapies and targeted therapies, which can potentially further prolong overall survival.

Involved field radiotherapy (IFRT) is considered to be the standard of care for palliative treatment of LM. Relevant to this, the US National Comprehensive Cancer Network (NCCN) 2017 guidelines for management of LM recommend Intrathecal Chemotherapy (IT) in combination with IFRT in patients with good prognosis disease (as defined by high performance status, non-fixed neurologic deficits, minimal systemic disease, and reasonable options for systemic disease treatment). Patients not meeting criteria for good prognosis are recommended to undergo IFRT to symptomatic sites or best supportive care (45). Up to now, no randomized clinical trial to assess the efficacy and tolerance of RT in LM have been conducted, however use of radiation therapy in NSCLC patients with LM, particularly in those not presenting driver mutations, needs to be better defined in clinical trials. Concomitant strategies with ITC are currently not considered as standard care due to the toxicity profile. Phase II clinical trial of combination therapy with involved field RT combined with concurrent intrathecal-MTX or intrathecal-ARAC is currently underway (57). 
Table 1 summarize the published studies from 2000: different types of radiation modality on different histologies in patients with $\mathrm{LM}$ are included $(36,49,56,58-61)$.

In the last few years, understanding of immune system's role in the response to ionizing radiation is progressively raising, novel opportunities to study how to combine immunotherapy with radiation-induced cell killing are revolutionizing cancer treatment. Accumulating preclinical and clinical data showed that combination of radiation techniques with immunotherapy stimulates immune response, improves locoregional and distant control finally resulting in better OS. Radiation appears to stimulate the immune system through multiple mechanisms, including the increase of the tumor-associated antigens (TAAs) availability, improving antigen presentation and subsequent stimulation of effector $\mathrm{T}$ cells, and enhancing infiltration of dentritic cells and $\mathrm{T}$ cells into the tumor microenvironment. The limited evidence for immunotherapy to date in the treatment of BM and LM stems from the deliberate exclusion of patients with active brain metastases from many large randomized trial assessing drug efficacy (61-63). However, comparable efficacy of immunotherapy agents in the brain and at extracerebral sites with radiation therapy has been recently reported by an ongoing study from Goldberg et al. In this initial analyses 36 cases were considered, 18 with melanoma and 18 with NSCLC. Patients were treated with pembrolizumab $10 \mathrm{mg} / \mathrm{kg}$ every 2 weeks until progression, no target lesions were previously resected, 20 patients received some form of local CNS therapy prior to enrollment ( 9 and
7 lesions had been treated respectively with WBRT and SRS, 75 lesions were untreated). The primary endpoint was BM response rate and the initial results presented demonstrated a systemic benefit from immunotherapy in patients with metastatic melanoma and NSCLC (61). Combining immunotherapeutic agents with stereotactic radiosurgery appears to enhance both local and distant control, and result in better survival (42).

Finally, other types of RT in patients without obstruction to CSF flow, as radioimmunotherapy (RIT) consisting of intra CSF administration of radioisotopes like iodine-131 $\left({ }^{131} \mathrm{I}\right)$ and yttrium-90 $\left({ }^{90} \mathrm{Y}\right)$ with radiolabeled antibodies as HMFG1, 3F8 and 8H9 have been utilized, but further improvement in the pharmacokinetic modeling of CNS RIT modality should refine this emerging therapy to fit the clinical context $(63,64)$.

\section{Systemic Therapy}

In the last decade, the advent of EGFR- tyrosine kinase inhibitors (TKIs) has improved the prognosis of NSCLC patients harboring EGFR mutations on both CNS metastases and extracranial disease, by contrast non-oncogene addicted NSCLC prognosis remains extremely poor.

The role of chemotherapy for patients with CNS metastases from NSCLC has been neglected for years, because of prevailing belief that chemotherapeutic drugs cannot cross at all the BBB. A Platinum based-combination (preceded or not by a local radiation treatment) is the mainstay of treatment in

TABLE 1 | Selected trials published of radiation modality treatment with or without chemotherapy/immunotherapy association in patients with LM/BM [BM, brain metastasis; LM, leptomeningeal metastasis, Involved-field radiotherapy (IF-RT), Intrathecal chemotherapy (IC), Craniospinal Irradiation (CSI) Methotrexate (MTX), Non available (NA), Not reached (NR), Patients (pt)].

\begin{tabular}{|c|c|c|c|c|c|c|}
\hline Author and year & $\begin{array}{l}\text { Number of } \\
\text { patients }\end{array}$ & Histology & $\begin{array}{l}\text { CNS } \\
\text { metastasis }\end{array}$ & $\begin{array}{l}\text { Status of EGFR/ALK } \\
\text { NSCLC }\end{array}$ & Treatment & $\begin{array}{l}\text { Median overall } \\
\text { survival (mOS) } \\
\text { (weeks) }\end{array}$ \\
\hline $\begin{array}{l}\text { Wolf et al. (56) } \\
\text { (retrospective) }\end{array}$ & 16 & $\begin{array}{l}8 \text { NSCLC } \\
5 \text { breast cancer } \\
3 \text { other }\end{array}$ & LM & $\begin{array}{l}4 \text { EGFR mutant } \\
1 \text { ALK-rearranged } \\
3 \text { no mutation }\end{array}$ & $\begin{array}{l}\text { SRS (5 pt had prior } \\
\text { WBRT) }\end{array}$ & 40 \\
\hline $\begin{array}{l}\text { Pan et al. (58) } \\
\text { (prospective phase } \\
2 \text { study) }\end{array}$ & 59 & $\begin{array}{l}32 \text { NSCLC } \\
10 \text { SCLC } 11 \\
\text { breast cancer } \\
6 \text { Other }\end{array}$ & LM & NA & $\begin{array}{l}\text { Concomitant IF-RT + } \\
\text { IC MTX }\end{array}$ & 26 \\
\hline $\begin{array}{l}\text { Ozdemir et al. (59) } \\
\text { (retrospective) }\end{array}$ & 51 & $\begin{array}{l}30 \text { SCC } \\
21 \text { Adenocarcinoma }\end{array}$ & LM & NA & WBRT & 15,6 \\
\hline $\begin{array}{l}\text { Brower et al. (60) } \\
\text { (retrospective) }\end{array}$ & 124 & $\begin{array}{l}32 \text { NSCLC } \\
22 \text { breast cancer } \\
21 \text { SCLC } \\
49 \text { other }\end{array}$ & LM & NA & $\begin{array}{l}\text { Chemotherapy + } \\
\text { WBRT }\end{array}$ & 9,2 \\
\hline $\begin{array}{l}\text { Gani et al. (49) } \\
\text { (retrospective) }\end{array}$ & 27 & $\begin{array}{l}20 \text { breast cancer } \\
7 \text { lung cancer }\end{array}$ & LM & NA & WBRT & 8,1 \\
\hline $\begin{array}{l}\text { Hermann et al. } \\
\text { (36) (retrospective) }\end{array}$ & 16 & $\begin{array}{l}9 \text { breast cancer } \\
5 \text { lung cancer } \\
2 \text { other }\end{array}$ & LM & NA & $\begin{array}{l}\text { CSI } \\
(10 \text { pt CSI + ITC MTX) }\end{array}$ & $\begin{array}{c}12 \\
8 \text { RT alone } \\
16 \text { RT-ITC }\end{array}$ \\
\hline $\begin{array}{l}\text { Goldberg et al. } \\
\text { (61) (two-cohort } \\
\text { phase II trial) }\end{array}$ & 36 & $\begin{array}{l}18 \text { melanoma } \\
18 \text { NSCLC }\end{array}$ & $\mathrm{BM}$ & $\begin{array}{l}\text { KRAS mutant } 4 \\
\text { EGFR mutant } 1 \\
\text { ALK-rearranged } 1 \\
\text { PD-L1 positive } 18\end{array}$ & $\begin{array}{l}\text { Pembrolizumab } \\
20 \text { pt prior CNS therapy } \\
\text { (9 lesions WBRT } 7 \\
\text { lesions SRS) }\end{array}$ & $\begin{array}{c}\text { Melanoma (NR) NSCLC } \\
30,8\end{array}$ \\
\hline
\end{tabular}


TABLE 2 | Platinum-based chemotherapy trials for CNS from NSCLC (BM, brain metastasis; LM, leptomeningeal metastasis).

\begin{tabular}{|c|c|c|c|c|c|c|}
\hline Author and year & $\begin{array}{l}\text { Number of } \\
\text { patients }\end{array}$ & CNS metastasis & Histology & Treatment & $\begin{array}{l}\text { Intracranial RR } \\
\text { (IRR, \%) }\end{array}$ & $\begin{array}{l}\text { Median overall survival } \\
\text { (mOS) (weeks) }\end{array}$ \\
\hline Robinet et al. (71) & 171 & BM & NSCLC & Cisplatin-Vinorelbine & 33 & 24 \\
\hline Franciosi et al. (68) & 43 & $B M+L M$ & NSCLC & Cisplatin-Etoposide & 37 & 32 \\
\hline Barlesi et al. (72) & 43 & BM & NSCLC & Cisplatin-Pemetrexed & 41.9 & 29.6 \\
\hline Cotto et al. (69) & 31 & BM & NSCLC & Cisplatin-Fotemustine & 23 & 16 \\
\hline Fujita et al. (67) & 30 & BM & NSCLC & Cisplatin-Ifosfamide-Irinotecan & 50 & 56 \\
\hline Bailon et al. (73) & 26 & BM & NSCLC & Carboplatin-Pemetrexed & 40 & 39 \\
\hline Cortes et al. (65) & 26 & BM & NSCLC & $\begin{array}{l}\text { Paclitaxel Cisplatin/Vinorelbine- } \\
\text { Gemcitabine }\end{array}$ & 38 & 21.4 \\
\hline Minotti et al. (66) & 23 & BM & NSCLC & Cisplatin-Teniposide & 35 & 21 \\
\hline Bernardo et al. (70) & 22 & BM & NSCLC & $\begin{array}{l}\text { Carboplatin-Vinorelbine- } \\
\text { Gemcitabine }\end{array}$ & 45 & 33 \\
\hline
\end{tabular}

advanced non-small cell lung cancer (aNSCLC) with BM and or LM NSCLC at diagnosis without oncogenic driver mutations or programmed death-ligand 1 (PD-L1) tumor proportion score (TPS) values $\geq 50 \%$ (65-73). Table 2 summarize platinum-based chemotherapy for NSCLC patients with CNS (65-73).

Pemetrexed is a compound currently approved both in combination with platinum in first-line setting and as a single agent in maintenance or second line setting for the treatment of non-squamous cell carcinoma (74-77). Although a penetration of CNS of less 5\%, pemetrexed demonstrated a consistent activity against BM from NSCLC with an intracranial RR of $30.8-41.9 \%$ and an overall clinical benefit of $63 \%$ without specific data for $\operatorname{LM}(72,73,78,79)$ Bevacizumab is an anti-VEGF monoclonal antibody approved in patients affected by locally advanced or metastatic non-squamous cell carcinoma (80). Recent reports showed that bevacizumab improve intra-tumor penetration of other chemotherapeutic agents, such as carboplatin or paclitaxel by normalizing angiogenesis at the tumor site with a low incidence of CNS hemorrhage $(81,82)$. Additionally, bevacizumab appeared to alter neuroimaging characteristics of LM, confounded diagnosis and possibly also influenced the pattern of tumor spread of LM (83). Bevacizumab is also known as a "steroid-sparing" drug, that allows reduction in steroid dosage and achieves reductions in mass effect and peritumoral edema getting better control of neurological symptoms (84). In those patients with squamous histology and low PD-L1 expression, gemcitabine and taxanes are largely prescribed, also in patient with $\mathrm{BM}$, but no specific data about LM are available (70, 85, 86).

For both squamous and non-squamous cell carcinoma without oncogene-addiction and TPS $\geq 50 \%$, pembrolizumab represents the standard of care in the first-line setting. Data on the efficacy of immunotherapy for BM or LM are currently limited, because of the exclusion of these patients from clinical trials $(38,87-89)$. In the trial by Goldberg et al., already mentioned above, 36 patients with BM were treated with pembrolizumab. Among patients with NSCLC, BM response rate was $33 \%$ and treatment-related serious adverse events were rare. Several aspects of study population need to be considered looking at the results: patients eligible for this trial were those with $\mathrm{BM}<20 \mathrm{~mm}$, asymptomatic and not requiring corticosteroids to control neurologic symptoms, without autoimmune disease and with no prior treatment with agents targeting PD-1/PD-L1 (61). Only preliminary data are available on efficacy of anti-programmed cell death 1 (PD-1) agents (nivolumab, pembrolizumab) or anti-PD ligand 1 (atezolizumab) in NSCLC patients with BM. A review on efficacy and safety of nivolumab conducted by Dudnik in five patients with aNSCLC with new/progressing asymptomatic CNS metastasis (including patient with LM) suggested that immune-check inhibitors might have an intracranial activity. Two intracranial responses were observed, while stabilization of LM was achieved in 10 weeks (90). In the Italian Nivolumab Squamous NSCLC Expanded Access Program, 38 patients with treated and asymptomatic BM were included, none of them with LM. In this subgroup of patients immunotherapic agent obtained a disease control rate equal to $47.3 \%$ (91). On the other hand, Otsubo et al., reported a case report of the development of LM during a pronounced response of the primary tumor to pembrolizumab therapy in a NSCLC patient (92). Relevant to this, in the era of molecular oncology it will be important to consider genomic differences in systemic malignancies that can implicate a distinct immune response.

Looking at other type of compounds, a phase II trial with abemaciclib (orally bioavailable inhibitor of cyclin-dependent kinases 4 and 6) (93) is ongoing in patients with LM from NSCLC and solid tumors (94).

\section{Intra-Thecal Chemotherapy}

Intrathecal administration is the most common method to deliver chemotherapeutic agents in non-nodular and nonbulky LM in solid tumors, although efficacy compared to systemic administration and choice of regimen are poorly understood due to limited randomized controlled trials (95). Systemic chemotherapy, which may be combined with intrathecal chemotherapy, remains standard treatment for lung cancer patients with LM and a good-risk profile (45). 
Several retrospective studies demonstrated a survival benefit from IT-therapy. Because of the paucity of available patients, LM studies often accrue multiple primary histologies. Most reports of intrathecal LM treatments include patients who simultaneously receive systemic agents $(29,95-98)$. Although the compounds routinely used for intra-CSF treatment do not have a key role as single agents for systemic treatment of most common cancers causing LM, three agents are commonly prescribed for the intrathecal treatment of LM: methotrexate (98), cytarabine (including liposomal cytarabine) $(99,100)$ or thioTEPA (8). Several schedules have been proposed, without agreement on optimal dose, frequency of administration or optimal duration of treatment. No intra-CSF agent has shown a significant survival advantage over another $(8,99,100)$. Up to now most of the patients are treated until progression or for 1 year, if tolerated. In the absence of evidence from appropriate clinical trials, clinical symptoms, MRI and CSF findings, as well as tolerance of treatment, guide individual decisions on the duration of treatment (34). Pemetrexed is a newer generation multitargeted anti-folate agent and, compared with methotrexate, has better tolerability, exhibits a more favorable side effect profile, and possesses fewer-drug interactions (78). A phase I trial (NCT03101579) is ongoing to define safety profile and clinical response rate associated with this specific intrathecal therapy (101).

\section{REFERENCES}

1. Levy A, Faivre-Finn C, Hasan B, De Maio E, Berghoff AS, Girard N, et al. Diversity of brain metastases screening and management in non-small cell lung cancer in Europe: Results of the European Organisation for Research and Treatment of Cancer Lung Cancer Group survey. Eur J Cancer (2018) 93:37-46. doi: 10.1016/j.ejca.2018.01.067

2. Soffietti R, Abacioglu U, Baumert B, Combs SE, Kinhult S, Kros $\mathrm{JM}$, et al. Diagnosis and treatment of brain metastases from solid tumors: guidelines from the European Association of Neuro-Oncology (EANO). Neuro-Oncology (2017) 19:162-74. doi: 10.1093/neuonc/ now241

3. Remon J, Le Rhun E, Besse B. Leptomeningeal carcinomatoses in non-small cell lung cancer patients; a continuing challenge in the personalized treatment era. Cancer Treat Rev. (2017) 53:158-37. doi: 10.1016/j.crtv.2016.12.006

4. Liao B-C, Lee J-H, Lin C-C, Chen Y-F, Chang C-H, Ho C-C, et al. Epidermal growth factor receptor tyrosine kinase inhibitors for nonsmall-cell lung cancer patients with leptomeningeal carcinomatosis. J Thorac Oncol. (2015) 10:1754-61. doi: 10.1097/JTO.00000000000 00669

5. Lee SJ, Lee JI, Nam DH, Ahn YC, Han JH, Sun JM, et al. Leptomeningeal carcinomatosis in non-small-cell lung cancer patients: impact on survival and correlated prognostic factors. J Thorac Oncol. (2013) 8:185-91. doi: 10.1097/JTO.0b013e3182773f21

6. Omuro AMP, Kris MG, Miller VA, Franceschi E, Shah N, Milton DT, et al. High incidence of disease recurrence in the brain and leptomeninges in patients with non small cell lung carcinoma after response to gefitinib. Cancer (2005) 103:2344-8. doi: 10.1002/cncr. 21033

7. Nugent JL, Bunn PA Jr, Matthews MJ, Ihde DC, Cohen MH, Gazdar A, et al. CNS metastases in small cell bronchogenic carcinoma: increasing frequency and changing pattern with lengthening survival. Cancer (1979) 44:1885-93.

\section{CONCLUSION}

LM is undoubtfully a serious complication in NSCLC patients. Prognosis remains poor, even with the use of personalized treatments, principally due to low penetration into the CSF of currently used agents. To our knowledge no randomized trial has demonstrated a clear survival benefit of any single modality in the treatment of LM. The optimal treatment strategy involves a multi- disciplinary approach. The increasing prevalence of LM warrants further investigation into therapies and prognostic variables to serve as a guide for treatment recommendations and patients counseling. An improved understanding of the biologic mechanisms underlying tumor CNS metastases and novel available diagnostic tools will allow for patient-tailored treatment strategies. Future welldesigned randomized controlled studies are needed to evaluate the efficacy of chemotherapeutics, immunotherapies and radiation treatment in this specific subgroup of patients and, more specifically, in those without an "oncogene addiction."

\section{AUTHOR CONTRIBUTIONS}

AT and AM wrote the manuscript with support from TV. SN supervised the manuscript.

8. Grossman SA, Finkelstein DM, Ruckdeschel JC, Trump DL, Moynihan T, Ettinger DS. Randomized prospective comparison of intraventricular methotrexate and thiotepa in patients with previously untreated neoplastic meningitis. Eastern Cooperative Oncology Group. J Clin Oncol. (1993) 11:561-9. doi: 10.1200/JCO.1993.11.3.561

9. Cheng H, Perez-Soler R. Leptomeningeal metastases in non-small-cell lung cancer. Lancet Oncol. (2018) 19:e43-55. doi: 10.1016/S1470-2045 (17) 30689-7

10. Hyun J-W, Jeong IH, Joung A, Cho HJ, Kim S-H, Kim HJ. Leptomeningeal metastasis: clinical experience of 519 cases. Eur J Cancer (2016) 56:107-14. doi: 10.1016/j.ejca.2015.12.021

11. Mak KS, Gainor JF, Niemierko A, Oh KS, Willers H, Choi NC, et al. Significance of targeted therapy and genetic alterations in EGFR, ALK or KRAS on survival in patients with non-small cell lung cancer treated with radiotherapy for brain metastases. Neuro Oncol. (2015) 17:296-302. doi: 10.1093/neuonc/noul46

12. Riess JW, Nagpal S, Iv M, Zeineh M, Gubens MA, Ramchandran K, et al. Prolonged survival of patients with non-small-cell lung cancer with leptomeningeal carcinomatosis in the modern treatment era. Clin. Lung Cancer (2014) 15:202-6. doi: 10.1016/j.cllc.2013.12.009

13. Du C, Hong R, Shi Y, Yu X, Wang J. Leptomeningeal metastasis from solid tumors: A single center experience in Chinese patients. J. Neuro Oncol. (2013) 115:285-91. doi: 10.1007/s11060-013-1228-x

14. Park JH, Kim YJ, Lee JO, Lee KW, Kim JH, Bang SM, et al. Clinical outcomes of leptomeningeal metastasis in patients with non-small cell lung cancer in the modern chemotherapy era. Lung Cancer (2012) 76:387-92. doi: 10.1016/j.lungcan.2011.11.022

15. Chamberlain MC, Baik CS, Gadi VK, Bhatia S, Chow LQ. Systemic therapy of brain metastases: non-small cell lung cancer, breast cancer, and melanoma. Neuro Oncol. (2017) 19:11-24:doi: 10.1090/neuonc/now197

16. Ostermann G, Csajka C, Buclin T, Leyvraz S, Lejeune F, Decosterd LA, et al. Plasma and cerebrospinal fluid population pharmacokinetics of temozolomide in malignant gliomas patients. Clin Cancer Res. (2004) 10:3728-36. doi: 10.1158/1078-0432.CCR-03-0807 
17. Shapiro WR, Young DF, Mehta BM. Methotrexate: distribution in the cerebrospinal fluid after intravenous, ventricular and lumbar injections. $N$ Eng J Med. (1975) 293:161-6. doi: 10.1056/NEJM197507242930402

18. Balis FM, Blaney SM, McCully Cl, Bacher JD, Murphy RF, Poplack DG. Methotrexate distribution within the subaracnoid space after inthaventricular and intravenous administration. Cancer Chemothet Pharmacol. (2000) 45:259-64. doi: 10.1007/s002800050038

19. Sung CA, Blaney SM, Cole DE, Balis FM, Dedrick RL. Pharmacokinetic model of topotecan clerance from plasma and cerebrospinal fluid. Cancer Res Cancer Res. (1994) 54:5118-22.

20. Serlin Y, Shelef I, Knyazer B, Friedman A. Anatomy and physiology of the blood-brain barrier. Semin Cell Dev Biol. (2015) 8:2-6. doi: 10.1016/j.semcdb.2015.01.002

21. Weidle UH, Niewöhner J, Tiefenthaler G. The Blood-Brain Barrier challenge for the treat of brain cancer, secondary brain metastasis, and neurological diseases. Cancer Genomics Proteomics (2015) 12:167-77.

22. Walbert T, Gilbert MR. The role of chemotherapy in the treatment of patients with brain metastases from solid tumors. Int J Clin Oncol. (2009) 14:299-306. doi: 10.1007/s10147-009-0916-1

23. Inno A, Di Noia V, D'Argento E, Modena A, Gori S. State of the art of chemotherapy for the treatment of central nervous system metastases from non-small cell lung cancer. Transl Lung Cancer Res. (2016) 5:599-609. doi: 10.21037/tlcr.2016.11.01

24. Holash J, Maisonpierre PC, Compton D, Boland P, Alexander CR, Zagzag D, et al. Vessel cooption, regression, and growth in tumors mediated by angiopoietins and VEGF. Science (1999) 284:1994-8. doi: 10.1126/science.284.5422.1994

25. Ahluwalia MS, Vogelbaum MV, Chao ST, Mehta MM. Brain metastasis and treatment. FI000Prime Rep. (2014) 6:114. doi: 10.12703/P6-114

26. Eichler AF, Chung E, Kodack DP, Loeffler JS, Fukumura D, Jain RK. The biology of brain metastases-translation to new therapies. Nat Rev Clin Oncol. (2011) 8:344-56. doi: 10.1038/nrclinonc.2011.58

27. Zeng YD, Liao H, Qin T, Zhang L, Wei WD, Liang JZ, et al. Blood-brain barrier permeability of gefitinib in patients with brain metastases from nonsmall-cell lung cancer before and during whole brain radiation therapy. Oncotarget (2015) 6:8366-76. doi: 10.18632/oncotarget.3187

28. Mack F, Baumert BG, Schäfer N, Hattingen E, Scheffler B, Herrlinger U, et al. Therapy of leptomeningeal metastasis in solid tumors. Cancer Treat Rev. (2016) 43:83-91. doi: 10.1016/j.ctrv.2015.12.004

29. Chamberlain M, Soffietti R, Raizer J, Rud R, Brandsma D, Boogerd W, et al. Leptomeningeal metastasis: a response assessment in neuro-oncology critical review of endpoints and response criteria of published randomized clinical trials. Neuro-Oncology (2014) 16:1176-85. doi: 10.1093/neuonc/ nou089

30. Grossman SA, Krabak MJ. Leptomeningeal carcinomatosis. Cancer Treat Rev. (1999) 25:103-19. doi: 10.1053/ctrv.1999.0119

31. Jiang BY, Li YS, Guo WB, Zhang XC, Chen ZH, Su J, et al. Detection of driver and resistance mutations in leptomeningeal metastases of NSCLC by nextgeneration sequencing of cerebrospinal fluid circulation tumour cells. Clin Cancer Res. (2017) 23:5480-8. doi: 10.1158/1078-0432.CCR-17-0047

32. Rodesch G, Van Bogaert P, Mavroudakis N, Parizel PM, Martin JJ, Segebarth $\mathrm{C}$, et al. Neuroradiologic findings in leptomeningeal carcinomatosis: the value interest of gadolinium-enhanced MRI. Neuroradiology (1990) 32:2632.

33. Salgarello M, Lunardi G, Inno A, Pasetto S, Severi F, Gorgoni G, et al. 18FNaF PET/CT imaging of brain metastases. Clin Nucl Med. (2016) 41:564-5. doi: 10.1097/RLU.0000000000001186

34. Le Rhun E, Weller M, Brandsma D, Van den Bent M, De Azambuja E, Henriksson R, et al. EANO-ESMO clinical practice guidelines for diagnoses, treatment and follow-up of patients with leptomeningeal metastases from solid tumours. Ann Oncol. (2017) 28 (Suppl. 4):iv84-99. doi: 10.1093/ annonc/mdx 221

35. Chamberlain MC. Leptomeningeal metastasis. Semin Neurol (2010) 30:23644. doi: 10.1055/s-0030-1255220

36. Hermann B, Hültenschmidt B, Sautter-Bihl ML. Radiotherapy of the neuroaxis for palliative treatment of leptomeningeal carcinomatosis. Strahlenther Onkol. (2001) 177:195-9. doi: 10.1007/s00066-001-0 803-9
37. Boogerd W, van den Bent MJ, Koehler PJ, Heimans JJ, van der Sande JJ, Aaronson NK, et al. The relevance of intraventricular chemotherapy for leptomeningeal metastasis in breast cancer: a randomized study. Eur J Cancer (2004) 40:2726-33. doi: 10.1016/j.ejca.2004.08.012

38. Herbst RS, Baas P, Kim D-W, Felip E, Pérez-Gracia JL, Han J$\mathrm{Y}$, et al. Pembrolizumab versus docetaxel for previously treated, PDL1-positive, advanced non-small-cell lung cancer (KEYNOTE-010): a randomized controlled trial. Lancet (2016) 387:1540-50. doi: 10.1016/S01406736(15)01281-7

39. Barlesi F, Keunchil P, Ciardiello F, von Pawel J, Gadgeel S, Hida T, et al. Primary analysis from OAK, a randomized phase III study comparing atezolizumab with docetaxel in advanced NSCLC, ESMO 2016. Ann Oncol. (2016) 27: ix139-ix156. doi: 10.1093/annonc/mdw594

40. Badiyan SN, Regine W, Mehta M. Stereotactic radiosurgery for treatment of brain metastases. Am Soc Clin Oncol. (2016) 12:703-12. doi: 10.1200/JOP.2016.012922

41. Lou E, Sperduto PW. Integrating bevacizumab and radiation treatment of brain metastases: is there sense and sensibility in this approach? Ann Transl Med. (2016) 4:36. doi: 10.3978/j.issn.2305-5839.2015.12.42

42. Zhang I, Formenti SC, Knisely IPS. Immunotherapy plus stereotactic radiosurgery: building on the promise of precision medicine for the $\mathrm{CNC}$ malignancies, part 1: principles of combined treatment. Oncology (2018) 35:e28-32.

43. Hee-Jun K, Seock-Ah L, Bhumsuk K, Yu-Jung K, Sae-Won H, Tae K, et al. Clinical outcome of central system metastases from breast cancer: differences in survival depending on systemic treatment. J Neuro-Oncol. (2012) 106:303-13. doi: 10.1007/s11060-011-0664-8

44. Altundag K, Bondy ML, Mirza NQ, Kau SW, Broglio K, Hortobagyi GN, et al. Clinicopathologic characteristics and prognostic factors in 420 metastatic breast cancer patients with central nervous system metastases. Cancer (2017) 110:2640-7. doi: $10.1002 / \mathrm{cncr} .23088$

45. Central Nervous System Cancers: Leptomeningeal Metastases (2017). v.1.2017: Available online at: http://www.nccn.org

46. Schimmel WCM, Verhaak E, Hanssens PEJ, Gehring K, Sitskoorn MM. A randomized trial to compare cognitive out come after gamma knife radiosurgery versus whole brain radiation therapy in patients with multiple brain metastases: research protocol CAR-study B. BMC Cancer (2018) 18:218. doi: 10.1186/s12885-018-4106-2

47. Espenel S, Vallard A, Langrand-Escure J, Ben Mrad M, Mery B, Rivoirard R, et al. Méningite carcinomateuse: le point de vue de l'oncologue radiothérapeute. Cancer/Radiothérapie (2016) 20:54-9. doi: 10.1016/j.canrad.2016.01.008

48. Waki F, Ando M, Takashima A, Yonemori K, Nokihara H, Miyake $\mathrm{M}$, et al. Prognostic factors and clinical outcomes in patients with leptomeningeal metastasis from solid tumors. J Neurooncol. (2009) 93:20512. doi: 10.1007/s1106-008-9758-3

49. Gani C, Muller AC, Eckert F, Schroeder C, Bender B, Pantazis G, et al. Outcome after whole brain radiotherapy alone in intracranial leptomeningeal carcinomatosis from solid tumors. Strahlenther Onkol. 188:148-53. doi: 10.1007/s00066-011-0025-8

50. Chamberlain MC. Neoplastic meningitis. Oncologist (2008) 13:967-77. doi: 10.1634/theoncologist.2008-0138

51. Ray GL, Buchsbaum JC, McMullen KP, Simoneaux RV, Hines M, Douglas JG, et al. Definitive treatment of leptomeningeal spinal metastases in children. Pediatr Blood Cancer (2013) 60:1839-41. doi: 10.1002/pbc. 24659

52. Chang EL, Maor MH. Standard and novel radiotherapeutic approaches to neoplastic meningitis. Curr Oncol Rep. (2003) 5:24-8.

53. Shaw E, Scott C, Souhami L, Dinapoli R, Kline R, Loeffler J, et al. Single dose radiosurgical treatment of recurrent previously irradiated primary brain tumors and brain metastases: final report of RTOG protocol 90-05. Int J Radiat Oncol Biol Phys. (2000) 47:291-8. doi: 10.1016/S0360-3016(99)00507-6

54. Brown PD, Pugh S, Laack NN, Wefel JS, Khuntia D, Meyers C, et al. Memantine for the prevention of cognitive dysfunction in patients receiving whole-brain radiotherapy: a randomized, double-blind, placebo-controlled trial. Radiation Therapy Oncology Group (RTOG). Neuro-Oncology (2013) 15:1429-37. doi: 10.1093/neuron/not114 
55. Bertke MH, Burton EC, Shaughnessy JN. Stereotactic radiosurgery as part as multimodal treatment in a bulky leptomeningeal recurrence of breast cancer. Cureus (2016) 8:e523. doi: 10.7759/cureus.523

56. Wolf A, Donahue B, Silverman JS, Chachoua A, Lee JK, Kondziolka D. Stereotactic radiosurgery for focal leptomeningeal disease in patients with brain metastases. J Neurooncol. (2017) 134:139-43. doi: 10.1007/s11060-017-2497-6

57. ClinicalTrials.gov Identifer: NCT03082144.

58. Pan Z, Yang G, He H, Zhao G, Yuan T, Li Y, et al. Concurrent radiotherapy and intrathecal methotrexate for treating leptomeningeal metastasis from solid tumors with adverse prognostic factors: a prospective and single-arm study. Int J Cancer (2016) 139:1864-72. doi: 10.1002/ijc.30214

59. Ozdemir Y, Yildirim BA, Topkan E. Whole brain radiotherapy in management of non-small-cell lung carcinoma associated leptomeningeal carcinomatosis: evaluation of prognostic factors. J Neurooncol. (2016) 129:329-35. doi: 10.1007/s11060-016-2179-9

60. Brower JV, Saha S, Rosenberg SA, Hullett CR, Ian Robins H. Management of leptomeningeal metastases: prognostic factors and associated outcomes. $J$ Clin Neurosci. (2016) 27:130-7. doi: 10.1016/j.jocn.2015.11.012

61. Goldberg SB, Gettinger SN, Mahajan A, Chiang AC, Herbst RS, Sznol M, et al. Pembrolizumab for patients with melanoma or non small-cell lung cancer and untreated brain metastases: early analysis of a non-randomized, open label phase 2 trial. Lancet Oncol. (2016) 17:976-83. doi: 10.1016/S14702045(16)30053-5

62. Long GV, Atkinson V, Menzies AM, Lo S, Guminski AD, Brown $\mathrm{MP}$, et al. A randomized phase II study of nivolumab or nivolumab combined with ipilimumab in patients with melanoma brain metastases: the Anti-PD1 Brain Collaboration (ABC). J Clin Oncol. (2017) 35:9508. doi: 10.1200/JCO.2017.35.15

63. Moseley RP, Benjamin JC, Ashpole RD, Sullivan NM, Bullimore JA, Coackham HB. Carcinomatous meningitis: antibody-guided therapy with I-131 HMFG1, J Neurol Neurosurg Psychiatry (1991) 54:260-5.

64. He P, Kramer K, Smith-Jones P, Zanzonico P, Humm J, Larson SM, et al. Two- compartment model of radioimmunotherapy delivered through cerebrospinal fluid. Eur J Nucl Med Mol Imaging (2011) 38:334-42. doi: 10.1007/s00259-010-1633-8

65. Cortes J, Rodriguez J, Aramendia JM, Salgado E, Gurpide A, GarciaFoncillas J, et al. Front-line paclitaxel/cisplatin-based chemotherapy in brain metastases from non-small-cell lung cancer. Oncology (2003) 64:28-35. doi: 10.1159/000066520

66. Minotti V, Crinò L, Meacci ML, Corgna E, Darwish S, Palladino MA, et al. Chemotherapy with cisplatin and teniposide for cerebral metastases in non-small cell lung cancer. Lung Cancer (1998) 20:93-8.

67. Fujita A, Fukuoka S, Takabatake H, Tagaki S, Sekine K. Combination chemotherapy of cisplatin, ifosfamide, and irinotecan with rhG-CSF support in patients with brain metastases from non-small cell lung cancer. Oncology (2000) 59:291-5. doi: 10.1159/000012185

68. Franciosi V, Cocconi G, Michiara M, Di Costanzo F, Fosser V, Tonato M, et al. Front-line chemotherapy with cisplatin and etoposide for patients with brain metastases from breast carcinoma, non-small-cell lung carcinoma, or malignant melanoma: a prospective study. Cancer (1999) 85:1599-605.

69. Cotto C, Berille J, Souquet PJ, Riou R, Croisile B, Turjman F, et al. A phase II trial of fotemustine and cisplatin in central nervous system metastases from non-small cell lung cancer. Eur J Cancer (1996) 32A:69-71.

70. Bernardo G, Cuzzoni Q, Strada MR, Bernardo A, Brunetti G, Jedrychowska I, et al. First-line chemotherapy with vinorelbine, gemcitabine, and carboplatin in the treatment of brain metastases from non-small-cell lung cancer: a phase II study. Cancer Invest. (2002) 20:293-302.

71. Robinet G, Thomas P, Breton JL, Léna H, Gouva S, Dabouis G, et al. Results of a phase III study of early versus delayed whole brain radiotherapy with concurrent cisplatin and vinorelbine combination in inoperable brain metastasis of non-small-cell lung cancer: Groupe Francais de PneumoCancerologie (GFPC) Protocol 95-1. Ann Oncol. (2001) 12:59-67.

72. Barlesi F, Gervais R, Lena H, Hureaux J, Berard H, Paillotin D, et al. Pemetrexed and cisplatin as first-line chemotherapy for advanced nonsmallcell lung cancer (NSCLC) with asymptomatic inoperable brain metastases: a multicenter phase II trial (GFPC 07-01). Ann Oncol. (2011) 22:2466-70. doi: 10.1093/annonc/mdr003
73. Bailon O, Chouahnia K, Augier A, Bouillet T, Billot S, Coman I, et al. Upfront association of carboplatin plus pemetrexed in patients with brain metastases of lung adenocarcinoma. Neuro Oncol. (2012) 14:491-5. doi: 10.1093/neuonc/nos004

74. Scagliotti GV, Parikh P, von Pawel J, Biesma B, Vansteenkiste J, Manegold $\mathrm{C}$, et al. Phase III study comparing cisplatin plus gemcitabine with cisplatin plus pemetrexed in chemotherapy-naive patients with advancedstage non-small-cell lung cancer. J Clin Oncol. (2008) 26:3543-51. doi: 10.1200/JCO.2007.15.0375

75. Ciuleanu T, Brodowicz T, Zielinski C, Kim JH, Krzakowski M, Laack $\mathrm{E}$, et al. Maintenance pemetrexed plus best supportive care versus placebo plus best supportive care for non-small-cell lung cancer: a randomised, double-blind, phase 3 study Lancet (2009) 374:1432-40. doi: 10.1016/S0140-6736(09)61497-5

76. Paz-Ares LG, De Marinis F, Dediu M, Thomas M, Pujol JL, Bidoli $\mathrm{P}$, et al. PARAMOUNT: Final overall survival results of the phase III study of maintenance pemetrexed versus placebo immediately after induction treatment with pemetrexed plus cisplatin for advanced nonsquamous non-small-cell lung cancer. J Clin Oncol. (2013) 31:2895-902. doi: 10.1200/JCO.2012.47.1102

77. Hanna N, Shepherd FA, Fossella FV, Pereira JR, De Marinis F, von Pawel J, et al. Randomized phase III trial of pemetrexed vs. docetaxel in patients with non-small-cell-lung cancer previously trated with chemotherapy. J Clin Oncol. (2004) 22:1589-97. doi: 10.1200/JCO.2004.08.163

78. Kumthekar P, Grimm SA, Avram MJ, Kaklamani V, Helenowski I. Pharmacokinetics and efficacy of pemetrexed in patients with brain or leptomeningeal metastases. J Neurooncol. (2013) 112:247-55. doi: 10.1007/s11060-013-1055-0

79. Bearz A, Garassino I, Tiseo M, Caffo, Soto-Parra H, Boccalon M, et al. Activity of Pemetrexed on brain metastases from Non-Small Cell Lung Cancer. Lung Cancer (2010) 68:264-8. doi: 10.1016/j.lungcan.2009.06.018

80. Sandler A, Gray R, Perry MC, Brahmer J, Schiller JH, Dowlati A, et al. Paclitaxel carboplatin alone or with bevacizumab for non-small-cell lung cancer. N Engl J Med. (2006) 355:2542-50. doi: 10.1056/NEJMoa061884.82

81. Socinski MA, Langer CJ, Huang JE, Kolb MM, Compton P, Wang L, et al. Safety of bevacizumab in patients with non-small-cell lung cancer and brain metastases. J Clin Oncol. (2009) 27:5255-61. doi: 10.1200/JCO.2009.22.0616

82. Kleinschmidt-DeMasters BK, Damek DM. The imaging and neuropathological effects of Bevacizumab (Avastin) in patients with leptomeningeal carcinomatosis. J Neurooncol. (2010) 96:375-84. doi: 10.1007/s11060-0099969-2

83. Mathews MS, Linskey ME, Hasso AN, Fruehauf JP. The effect of bevacizumab (Avastin) on neuroimaging of brain metastases. Surg Neurol. (2008) 70:649-52, discussion 53. doi: 10.1016/j.surneu.2007.06.029

84. Nghiemphu PL, Liu W, Lee Y, Than T, Graham C, Lai A, et al. Bevacizumab and chemotherapy for recurrent glioblastoma: a single-institution experience. Neurology (2009) 72:1217-22. doi: 10.1212/01.wnl.0000345668.03039.90

85. Edelman MJ, Belani CP, Socinski MA, Ansari RH, Obasaju CK, Chen R, et al. Outcomes associated with brain metastases in a three-arm phase III trial of gemcitabine-containing regimens versus paclitaxel plus carboplatin for advanced non-small cell lung cancer. J Thorac Oncol. (2010) 5:110-6. doi: 10.1097/JTO.0b013e3181c59a3a

86. Volk V, Cathomas R, Mark M, von Moos R, Klingbiel D, Brossart P, et al. Weekly carboplatin in combination with weekly paclitaxel in the treatment of metastatic non-small cell lung cancer: a single center 10-year experience. Support Care Cancer (2016) 24:2119-28. doi: 10.1007/s00520-015-3015-z

87. Brahmer J, Reckamp KL, Baas P, Crinò L, Eberhardt WE, Poddubskaya E, et al. Nivolumab versus Docetaxel in Advanced Squamous-Cell Non-Small-Cell Lung Cancer. N Engl J Med. (2015) 373:123-35. doi: 10.1056/NEJMoa1504627

88. Borghaei H, Paz-Ares L, Horn L, Spigel DR, Steins M, Ready NE, et al. Nivolumab versus Docetaxel in Advanced Nonsquamous Non-Small-Cell Lung Cancer. N Engl J Med. (2015) 373:1627-39. doi: 10.1056/NEJMoa1507643

89. Rittmeyer A, Barlesi F, Waterkamp D, Park K, Ciardiello F, von Pawel $\mathrm{J}$, et al. Atezolizumab versus docetaxel in patients with previously treated non-small-cell lung cancer (OAK): a phase 3, open-label, 
multicentre randomised controlled trial. Lancet (2017) 389:255-65. doi: 10.1016/S0140-6736(16)32517-X

90. Dudnik E, Yust-Katz S, Nechushtan H, Goldstein DA, Zer A, Flex $D$, et al. Intracranial response to nivolumab in NSCLC patients with untreated or progressing CNS metastases. Lung Cancer (2016) 98:114-7. doi: 10.1016/j.lungcan.2016.05.031

91. Crinò L, Bidoli P, Delmonte A, Grossi F, De Marinis F, Sperandi F, et al. Italian cohort of nivolumab Expanded Access Programme (EAP): efficacy and safety data from a real-world population Ann Oncol. (2016) 27(suppl. 4):iv3. doi: 10.1093/annonc/mdw332.01

92. Otsubo K, Seki N, Nakanishi Y, Okamoto I. Development of leptomeningeal carcinomatosis during a marked response of brain metastases to pembrolizumab in a patient with non-small-cell lung cancer. Ann Oncol. (2017) 29: 780-1. doi: 10.1093/annonc/mdx700

93. Hall M, Peters G. Genetic alterations of cyclins, cyclin-dependent kinases, and CDK inhibitors in human cancer. Adv Cancer Res. (1996) 68:67-108.

94. Patnaik A, Rosen LS, Tolaney SM, Tolcher AW, Goldman JW, Gandhi L, et al. Efficacy and Safety of Abemaciclib, an Inhibitor of CDK4 and CDK6, for Patients with Breast Cancer, Non-Small Cell Lung Cancer, and Other Solid Tumors. Cancer Discov. (2016) 6:740-53. doi: 10.1158/2159-8290.CD-16-0095

95. Chamberlain MC, Kormanik PR. Carcinoma meningitis secondary to nonsmall cell lung cancer: combined modality therapy. Arch Neurol. (1998) 55:506-12.

96. Chamberlain MC, Kormanic PR. Carcinomatous meningitis secondary to breast cancer: predictors of response to combined modality therapy. $J$ Neurooncol. (1997) 35:55-64.
97. Grant R, Naylor B, Greenberg HS. Clinical outcome in aggressively treated meningeal carcinomatosis. Arch Neurol. (1994) 51:457-61. doi: 10.1001/archneur.1994.00540170033013

98. Ahn HK, Han B, Lee SJ, Lim T, Sun JM, Ahn JS, et al. ALK inihibitor crizotinib combined with intrathecal methotrexate treatment for non-small cell lung cancer with leptomeningeal carcinomatosis. Lung Cancer (2012) 76:253-4. doi: 10.1016/j.lungcan.2012.02.003

99. Glantz MJ, Jaeckle KA, Chamberlain MC, Phuphanich S, Recht L, Swinnen LJ, et al. A randomized controlled trial comparing intrathecal sustained-release cytarabine (DepoCyt) to intrathecal methotrexate in patients with neoplastic meningitis from solid tumors. Clin Cancer Res. (1999) 5:3394-402.

100. Hoffmann AL, Buhk JH, Strik H. Neoplastic meningitis from breast cancer: feasibility and activity of long-term intrathecal liposomal Ara-C combined with dose-dense temozolomide. Anticancer Res. (2009) 29:5191-5.

101. ClinicalTrials.gov Identifer: NCT03101579.

Conflict of Interest Statement: The authors declare that the research was conducted in the absence of any commercial or financial relationships that could be construed as a potential conflict of interest.

Copyright (c) 2018 Turkaj, Morelli, Vavalà and Novello. This is an open-access article distributed under the terms of the Creative Commons Attribution License (CC BY). The use, distribution or reproduction in other forums is permitted, provided the original author(s) and the copyright owner(s) are credited and that the original publication in this journal is cited, in accordance with accepted academic practice. No use, distribution or reproduction is permitted which does not comply with these terms. 